\title{
Correction to: Urban design and informal settlements: placemaking activities and temporary architectural interventions in BaSECo compound
}

Francesco Rossini ${ }^{1}$

(c) Springer Nature Limited 2021

\section{Correction to: URBAN DESIGN International https://doi.org/10.1057/s41289-021-00168-4}

Due to an unfortunate oversight the sentence 'The results of the upgrading strategy suggest that 'action research' can become a strategic tool for experimenting with alternative strategies in the revitalisation of informal settlements' in the abstract section should read:

'The results of this work suggest that 'action research' can become a critical tool for experimenting with alternative strategies in the revitalisation of informal settlements'.

The original article has been corrected.
The original article can be found online at https://doi.org/10.1057/ s41289-021-00168-4.

Francesco Rossini

rossini@cuhk.edu.hk

1 School of Architecture, The Chinese University of Hong Kong, Room 302, Lee Shau Kee Architecture Building, Shatin, NT, Hong Kong
Publisher's Note Springer Nature remains neutral with regard to jurisdictional claims in published maps and institutional affiliations. 